\title{
Electrodeposition of high aspect ratio single crystalline tellurium nanowires from piperidinium-based ionic liquid
}

Laura Thiebaud $^{1}$, Sophie Legeai*1 ${ }^{1}$ Jaafar Ghanbaja ${ }^{2}$, Nicolas Stein ${ }^{1}$

${ }^{1}$ Institut Jean Lamour, UMR CNRS 7198, Université de Lorraine, 1 boulevard Arago, 57078 Metz Cedex 3, France

${ }^{2}$ Institut Jean Lamour, UMR CNRS 7198, Université de Lorraine, Parc Saurupt, 54011 Nancy, France

* Corresponding author. Tel.: +33 387315463.

E-mail address: sophie.legeai@univ-lorraine.fr (S. Legeai).

\section{Abstract}

Template-free electrodeposition of high aspect ratio Te nanowires is presented. Nanowires were obtained from the ionic liquid 1-ethyl-1-octyl-piperidinium bis(trifluoromethylsulfonyl)imide (EOPipTFSI) containing 1-ethyl-1-octyl-piperidinium bromide (EOPipBr). The influence of the EOPipBr content on the dimensions and the morphology of the nanostructures was studied. Several micrometers long tellurium nanowires with diameters between 100 and $180 \mathrm{~nm}$ were obtained when the EOPipBr content of the electrolyte is higher than $0.5 \mathrm{~mol} \%$. By decreasing the bromide concentration, the electrochemical behavior of $\mathrm{Te}^{\mathrm{IV}}$ solutions becomes more complex, leading to several reduction signals. By varying the applied overpotential, hair-like single crystalline nanowires can then be obtained with a diameter which can reach $50 \mathrm{~nm}$ and a length of $70 \mu \mathrm{m}$ leading to a high aspect ratio of almost 2000.

Keywords: Electrodeposition, Nanowires, Tellurium, Ionic liquid, Template-free 
High Resolution Transmission Electron Microscopy analyses show that the nanostructures are single crystalline and reveal a growth along the $c$-axis, with a smooth interface. No surface contaminants were observed by Scanning Transmission Electron Microscopy, proving that halide ions do not play the role of capping agents.

Keywords: Tellurium, Nanowires, Ionic liquid, Electrodeposition

\section{Introduction}

Tellurium (Te) compounds can be used in thermoelectric devices, where they convert heat into electricity and conversely. When the diameter of a material is constrained to the nanometer scale and its length is several orders of magnitude larger, the material can be considered as a one-dimensional nanostructure and the thermoelectric conversion efficiency can be significantly improved [1-4]. Indeed, the decrease of one dimension to the characteristic length scales of the material like the exciton Bohr radius and the phonon mean free path allows increasing the Seebeck coefficient and reducing the lattice thermal conductivity by phonon surface scattering respectively.

Electrodeposition of nanowires usually needs the use of a porous template [5, 6]. The growth takes places in the template pores whose geometries allow to control the shape and the size of nanowires. However, template-assisted electrodeposition involves multiples fabrication steps, like the preparation of the template and its removal. A single step template-free electrodeposition would be more convenient and easier for a further use of the nanowires. It has been shown in literature that ionic liquids, in addition to have high electrochemical and thermal stabilities, can act as capping agents allowing the formation of nanostructures without using a template [7-10]. Very few works deal with Te nanowires electrodeposition in roomtemperature ionic liquids (RTILs). Only Al-Salman [11] and co-workers have recently synthesized long polycrystalline Te nanowires of several micrometers in length with low 
diameters ranging between 25 and $35 \mathrm{~nm}$ in the 1-butyl-1-methylpyrrolidinium bis(trifluoromethylsulfonyl)imide ionic liquid containing $\mathrm{SiCl}_{4}$. The authors observed nanostructuring of Te deposits only in the presence of $\mathrm{SiCl}_{4}$ and concluded that this salt acts as a capping agent that promotes the growth of Te nanowires. However, the use of $\mathrm{SiCl}_{4}$ leads to the presence of an amorphous passivating layer on the nanowires surface which could affect the electronic properties of the material.

In a previous work [12], we showed that free standing single crystalline Te nanowires can be obtained in a piperidinium-based ionic liquids mixture: EOPipTFSI:EOPipBr 95:5 (mol:mol) (1-ethyl-1-octylpiperidinium cation, bis(trifluoromethylsulfonyl)imide and bromide anions). More recently [13], we showed that the shape and the size of the deposited nanostructures can be controlled by varying some experimental parameters that influence the deposition kinetics, namely applied potential and $\mathrm{Te}^{\mathrm{IV}}$ concentration. Using low concentration conditions and under diffusional control, we obtained self-standing nanowires with a mean length of $1.72 \pm$ $0.15 \mu \mathrm{m}$ and a mean diameter of $132 \pm 13 \mathrm{~nm}$ leading to a moderate aspect ratio of $13.2 \pm$ 2.4, which turn into hollow nanostructures in high overpotential conditions due to an insufficient species supply at the electrode.

In this work, the synthesis of high aspect ratio Te nanowires was obtained by varying the halide content in the electrolyte. We first present a voltammetric study of the influence of EOPipBr content on the electrochemical system $\mathrm{Te}^{\mathrm{IV}} / \mathrm{Te}^{0}$. It appears that in pure EOPipTFSI or for very low amount of EOPipBr, a complex voltammetric behavior is observed. Several reduction signals appear before bulk deposition, all corresponding to the reduction of $\mathrm{Te}^{\mathrm{IV}}$ in $\mathrm{Te}^{0}$. The influence of EOPipBr content on the morphology of nanostructures deposited at bulk deposition potential is then presented as well as the influence of applied potential for low EOPipBr content. 


\section{Experimental}

$\mathrm{TeCl}_{4}\left(99 \mathrm{~mol} \%\right.$, Alfa Aesar) was used as $\mathrm{Te}^{\mathrm{IV}}$ precursor. EOPipTFSI and EOPipBr were synthesized according to $[14,15]$, characterized by nuclear magnetic resonance analysis (Bruker Spectrospin $300 \mathrm{MHz}$ ) and stored in an argon filled glove box (MBraunLabstar; $\mathrm{O}_{2} / \mathrm{H}_{2} \mathrm{O}$ levels $\left.<1 \mathrm{ppm}\right)$. As the viscosity is high at room temperature, ranging from 400 to $1400 \mathrm{mPa}$.s depending on EOPipBr content, but strongly decreases with the temperature to reach 15 to $20 \mathrm{mPa} . \mathrm{s}$, the experiments were performed at $100^{\circ} \mathrm{C}$ [16]. Moreover, in our previous studies [12], we showed that a better crystallinity of the deposits is obtained at this temperature.

Electrochemical experiments were performed in a glove box using a Biologic potentiostat (VSP300). A platinum (Pt) disk (Metrohm) with a diameter of $3 \mathrm{~mm}$ and a Pt wire (Radiometer) were used respectively as working and counter electrodes along with an $\mathrm{Ag}^{\mathrm{I}} / \mathrm{Ag}^{0}$ reference electrode (RE) for voltammetric studies. This reference electrode consists in a $1 \mathrm{~mm}$ Ag wire (Alfa Aesar) immersed in a $10 \mathrm{mM} \mathrm{Ag}\left(\mathrm{CF}_{3} \mathrm{SO}_{3}\right)$ solution in $\mathrm{BMICF}_{3} \mathrm{SO}_{3}$ (1-butyl-1-methylimidazolium trifluoromethanesulfonate) ionic liquid. The reference electrode (RE) is placed in a glass capillary which is separated from the electrochemical cell by a glass frit. Voltammetric curves were obtained by scanning the potential from the open circuit potential towards the negative direction. Platinum-coated glass slides $(25 \times 10 \times 1 \mathrm{~mm}$, Pt coating thickness $300 \mathrm{~nm}$ ), supplied by Applications Couches Minces (ACM), were used both as working and counter electrodes for electrodeposition experiments. A Pt wire quasi reference electrode (QRE) was used for potentiostatic deposition, instead of the $\mathrm{Ag}^{\mathrm{I}} / \mathrm{Ag}^{0} \mathrm{RE}$, to avoid $\mathrm{Ag}^{\mathrm{I}}$ species diffusion towards the bulk solution that could lead to $\mathrm{Ag}^{0}$ co-deposition. A voltammetric curve was systematically recorded with the Pt QRE before each deposition experiment. The volume of the bath was equal to $5 \mathrm{~mL}$ leading to an immersed slide surface 
of $0.5 \mathrm{~cm}^{2}$. Deposits were thoroughly rinsed three times with acetone and dried under air before analysis.

The morphology of the deposits was analyzed by Scanning Electron Microscopy (SEM, Philips XL30 S FEG) at $5 \mathrm{kV}$. Transmission Electron Microscopy (TEM) investigations were carried out using a JEM - ARM 200F Cold Field Emission Gun operating at $200 \mathrm{kV}$ (point resolution $0.19 \mathrm{~nm}$ in TEM mode) fitted with a GIF Quantum ER. The growth direction of the nanostructures was determined by selected area electron diffraction (SAED). The diffraction spots were indexed according to the JCPDS card No. 36-1452 of the tellurium hexagonal phase. The crystalline structure of the deposits was investigated by X-ray powder diffraction measurements (XRD, Bruker D8Advance) with $\mathrm{Cu} \mathrm{K}_{\alpha}$ radiation $(\lambda=1.5406 \AA)$ at $40 \mathrm{kV}$ and $40 \mathrm{~mA}$.

3. Results and Discussion

3.1. Study of the electrochemical behavior of $\mathrm{Te}^{\mathrm{IV}}$ as a function of EOPipBr content

The electrochemical window of the electrolyte with and without EOPipBr is presented in Figure 1. In the presence of EOPipBr, two anodic signals are observed corresponding to $\mathrm{Br}^{-}$ oxidation, as already reported by Yamagata et al. in a 1-butyl-1-methylpyrrolidinium ionic liquid [17]. The oxidation of $\mathrm{Br}^{-}$occurs in two steps, probably corresponding to the following reactions, as observed in other aprotic media [18, 19]:

$3 \mathrm{Br}^{-} \rightarrow \mathrm{Br}_{3}^{-}+2 \mathrm{e}^{-} \quad(\mathrm{Eq} 1)$

$2 \mathrm{Br}_{3}^{-} \rightarrow 3 \mathrm{Br}_{2}+2 \mathrm{e}^{-}(\mathrm{Eq} 2)$

and occurring respectively for $\mathrm{E}>0.30 \mathrm{~V}$ and $\mathrm{E}>0.71 \mathrm{~V}$ vs $\mathrm{Ag}^{\mathrm{I}} / \mathrm{Ag}$, respectively. 
The influence of EOPipBr content (up to 80:20 (mol:mol)) on the electrochemical behavior of tellurium was studied at a $\mathrm{Te}^{\mathrm{IV}}$ concentration of $5 \mathrm{mM}$ corresponding to the solubility of $\mathrm{TeCl}_{4}$ at $100^{\circ} \mathrm{C}$ in pure EOPipTFSI without EOPipBr. Moreover, we have shown in a previous study that the lower the $\mathrm{Te}^{\mathrm{IV}}$ concentration, the higher the aspect ratio [13]. The corresponding voltammograms are presented in Figure 2.

One can observe that the open circuit potential shift to more positive values as the EOPipBr content decreases. As the OCP lies between the reduction of Te(IV) species and the oxidation of $\mathrm{Br}^{-}$ions, this could be interpreted as a change in $\mathrm{Te}(\mathrm{IV})$ speciation, namely the formation $\mathrm{Te}(\mathrm{IV})$ halogenated-Te(IV) complexes of lower stability as EOPipBr content decreases. This hypothesis is reinforced by the differences between the voltammetric curves presented in Figure 2. For an EOPipBr content $\geq 0.5 \mathrm{~mol} \%$, the shape of the voltammograms is similar and presents two reduction peaks : $\mathrm{C}_{1}$ and $\mathrm{C}_{2}$ which correspond respectively to the reduction of $\mathrm{Te}^{\mathrm{IV}}$ into $\mathrm{Te}^{0}$ and of $\mathrm{Te}^{0}$ into $\mathrm{Te}^{-\mathrm{II}}$ according to the literature [20, 21]. This latter signal represents the limit for the deposition of $\mathrm{Te}^{0}$ films. The $\mathrm{C}_{1}$ peak shifts to more negative values as the halide content increases (from $-0.58 \mathrm{~V}$ to $-0.67 \mathrm{~V}$ vs $\mathrm{Ag}^{\mathrm{I}} / \mathrm{Ag}^{0}$ ).

For EOPipBr $\leq 0.2 \mathrm{~mol} \%$, the reduction behavior of $\mathrm{Te}^{\mathrm{IV}}$ is clearly different. In the $0.2 \mathrm{~mol} \%$ EOPipBr solution, a second reduction signal appears at $-0.15 \mathrm{~V}$ vs $\operatorname{Ag}^{\mathrm{I}} / \mathrm{Ag}^{0}\left(\mathrm{C}_{1}{ }^{1}\right)$. In the solution free of EOPipBr, namely in pure EOPipTFSI ionic liquid, we can observe two additional reduction peaks at $0.18 \mathrm{~V}\left(\mathrm{C}_{1},\right)$ and $-0.18 \mathrm{~V}\left(\mathrm{C}_{1}{ }^{\prime}\right) \mathrm{vs} \mathrm{Ag}^{\mathrm{I}} / \mathrm{Ag}^{0}$. The presence of these peaks at more positive potentials values is responsible for the positive shift of the OCP. XRD analyses of deposits obtained at $\mathrm{C}_{1}$, and $\mathrm{C}_{1}$ " peak potential values confirm that $\mathrm{Te}^{0}$ was obtained in both cases proving that these signals correspond to the reduction of $\mathrm{Te}^{\mathrm{IV}}$ in $\mathrm{Te}^{0}$.

These multiple signals could be related to the speciation of $\mathrm{Te}^{\mathrm{IV}}$ that can exist under several $\mathrm{TeX}_{\mathrm{y}}{ }^{4-\mathrm{y}}$ forms in halide containing solutions, the value of $y$ depending on the halide content and $\mathrm{TeX}_{6}{ }^{2-}$ being the complex supposed to be predominant in halide-rich media [20]. In order to support this hypothesis, the Table 1 presents the ratio values of $\mathrm{X}^{-}$to $\mathrm{Te}^{\mathrm{IV}}$ concentrations in the different tested ionic liquid mixtures. 
Only one signal is observed in high EOPipBr content media $(\geq 0.5 \mathrm{~mol} \%)$, in which $\mathrm{Te}^{\mathrm{IV}}$ probably exists as $\mathrm{TeX}_{6}{ }^{2-}$ and we can assume that the following reaction occurs [20]:

$\mathrm{TeX}_{6}^{2-}+4 \mathrm{e}^{-} \rightarrow \mathrm{Te}^{0}+6 \mathrm{X}^{-}$

In pure EOPipTFSI or for low halide contents, $\mathrm{Te}^{\mathrm{IV}}$ probably exists under lower halidecoordinated complexes that are reduced at less negative potential values than $\mathrm{TeX}_{6}{ }^{2-}$. The presence of several signals could be due to the co-existence of several species in the ionic liquid, as supposed by Saha et al. [22] in the case of Se. Another hypothesis can be made, that was proposed by several authors that already observed this kind of behavior using halide salts in TFSI-based ionic liquids (In [2], Ta [23] and Sb [24] electrochemical studies). The formation of the $\mathrm{Te}^{0}$ deposit by halide-complexes reduction generates halide ions (Eq 3$)$. In these poorhalide media, this leads to a significant increase of halide ions concentration in the vicinity of the electrode. Considering that ionic liquids are viscous media in which the mass transport is very slow, this enrichment could be responsible of the multiple signals observed, due to the formation of higher halide complexes that would be reduced at more negative potential values $\left(\mathrm{C}_{1}\right.$, and $\left.\mathrm{C}_{1}\right)$.The $\mathrm{C}_{1}$ peak would correspond to the reduction of $\mathrm{TeX}_{6}^{2-}$ regardless of halide content, according to its potential value. These hypotheses concerning Te(IV) speciation will be checked in further work by Raman analyses that allow to determine the speciation of Te(IV) in the electrolyte (ref Raman milieu aq $1967 \mathrm{TeBrCl}$ )

One can also observe on Figure 1 a hysteresis that appears as the bromide content decreases, due to a higher capacitive current. This can be highlighted by varying the scan rate v (not shown here $)$ : as the EOPipBr content decreases, the slope of $\log (v)=f(\log i)$ deviates from 0.5 and increases, indicating a surface-controlled current. This is probably due to a difference in the double layer structure as the composition of the electrolyte changes. Endres and coworkers have shown by STM analysis that the anions of ionic liquids can be strongly 
adsorbed at the electrode, and so the nature of the anion can play a role in the double layer structure [25].

3.2.Influence of EOPipBr content on the morphology of Te deposits

Te electrodeposition was first studied by applying a potential value corresponding to the most negative peak $\left(\mathrm{C}_{1}\right)$ in pure EOPipTFSI and for the different EOPipBr content $(\mathrm{mol} \%)$ corresponding to the voltammetric study presented in Figure 2. The surface of obtained deposits is entirely covered of nanowires whatever the electrolyte composition. All the deposits SEM images are then not shown here, and the Figure 3 only presents images of the deposits obtained in pure EOPipTFSI and for three EOPipBr contents.

One can observe in Figure 3 that the nanowires obtained in pure EOPipTFSI are thinner and not faceted compared to those obtained in the presence of EOPipBr. All obtained deposits with EOPipBr content ranging from 0.5 to $20 \mathrm{~mol} \%$ present the same kind of morphology. The nanowires present a hexagonal shape characteristic of the crystallographic structure of the elemental Te (space group $\mathrm{P} 3{ }_{1} 21$ ). All the nanowires are single crystalline and grow along the [001] direction whatever the electrolyte composition. Figure 4 presents an example of selected TEM image and corresponding SAED diffractogram.

A statistic study of TEM images was carried out on a dozen of nanostructures per image to determine the mean dimensions of nanowires (length and diameter) as a function of EOPipBr content. Corresponding values and calculated aspect ratio are presented in Figure 5.

One can observe on Figure 5 that the diameter of the nanowires increases with EOPipBr content, the thinner nanowires being obtained in pure EOPipTFSI, around $40 \pm 20 \mathrm{~nm}$ in diameter for a mean length of $2.5 \pm 0.5 \mu \mathrm{m}$ leading to the best aspect ratio of $92 \pm 58$. The evolution of the nanowire length is more complex. The nanowires obtained in pure EOPipTFSI and for a low EOPipBr content $(0.2 \mathrm{~mol} \%)$ are much longer that those obtained 
for higher bromide contents. For EOPipBr $\geq 0.5 \mathrm{~mol} \%$, the length is lower that for lower contents but increases then with EOPipBr concentration for higher contents. As nanowires grow then in diameter as much as in length, the aspect ratio remains constant around $14 \pm 1$.

In these overpotential conditions $\left(\mathrm{C}_{1}\right.$ peak), we can thus distinguish two kind of nanowires: the longest nanowires obtained in pure EOPipTFSI and at low bromide concentration $(0.2$ mol\%) that reach high aspect ratios (92 and 36, respectively) and the ones obtained with higher EOPipBr content $(\geq 0.5 \mathrm{~mol} \%)$ which are faceted and have an mean aspect ratio of 13.5 .

As observed in Figure 2, in the case of low bromide content $(0.2 \mathrm{~mol} \%)$ and in pure EOPipTFSI, additional reduction signals are observed $\left(\mathrm{C}_{1}\right.$ ", and $\left.\mathrm{C}_{1}{ }^{\prime}\right)$. Deposits were then realized at each peak potential for each electrolyte composition. Corresponding SEM images are shown in Figure $6\left(\mathrm{C}_{1}{ }^{\prime}\right)$ and Figure $7\left(\mathrm{C}_{1}{ }^{\prime}\right)$.

In pure EOPipTFSI (Figure 6), the deposit obtained at the less negative peak $\mathrm{C}_{1}$ " presents a morphology different from what was previously observed. The substrate is poorly covered of longer and larger nanowires laying on the surface, between 30 and $70 \mu \mathrm{m}$ in length, and around $194 \pm 20 \mathrm{~nm}$ in diameter, that tend to agglomerate.

As previously observed on Figure 6, both deposits obtained at $\mathrm{C}_{1}$, are composed of mixed long hair-like nanowires laying down on the surface, but denser and much thinner than those obtained at $\mathrm{C}_{1}$ ", peak potential. Without bromide (Figure 7a), the interconnected nanowires present a diameter of $60 \pm 30 \mathrm{~nm}$ and a mean length of $3.65 \pm 0.35 \mu \mathrm{m}$. With the addition of a low amount of EOPipBr (Figure 7b), the deposit seems to better cover the surface. It is composed of $70 \pm 10 \mu \mathrm{m}$ long nanowires with a low diameter which reaches $50 \pm 20 \mathrm{~nm}$ leading to a high aspect ratio of almost 2000. These morphological characteristics are promising for thermoelectric performances that are currently under evaluation. 
We have realized TEM (Figures 8a and 8b) and HRTEM (Figure 8c) studies of the deposit presented in Figure 7b.

The HRTEM analyses show that the hair-like structures are single crystalline with a smooth surface (Figure 8c). No halide-containing surface layer was observed unlike observed in other works [11]. The Te crystallographic structure is highlighted with the image of inverse FFT (Figure 8d). The atomic arrangement is clearly displayed and a good agreement is observed with the (100) orthogonal projection of the hexagonal extended cell of Te. Thus the white spots correspond to the atoms having the same relative coordinates along the [001] axis, which are colored in red in the schematic cell. On both sides are placed gray spots, corresponding to atoms in blue with other coordinates. Moreover the interplanar distance $\mathrm{d}_{001}$ was identified and measured equal to $0.59 \mathrm{~nm}$. All these observations show unambiguously that the growth direction is along the c-axis and that these nanowires are single crystalline with no local defects.

\section{Conclusion}

We have shown in this study that single crystalline Te nanowires can be obtained in EOPipTFSI ionic liquid whatever the electrolyte composition, namely with or without the addition of halides by the mean of EOPipBr. Self-standing faceted nanowires are obtained for EOPipBr concentration higher than $0.5 \%$. By decreasing the bromide concentration, the speciation of $\mathrm{Te}^{\mathrm{IV}}$ probably changes and depending on the involved $\mathrm{Te}^{\mathrm{IV}}$ species, hair-like nanowires can be deposited, that are exempt of surface contaminant. The hair-like nanowires obtained using a low EOPipBr content electrolyte $(0.2 \mathrm{~mol} \%)$ are the most promising for thermoelectric applications with their low diameter and their high aspect ratio. 
References

[1] L.D. Hicks, M.S. Dresselhaus, EFFECT OF QUANTUM-WELL STRUCTURES ON THE THERMOELECTRIC FIGURE OF MERIT, Physical Review B, 47 (1993) 1272712731.

[2] A.I. Boukai, Y. Bunimovich, J. Tahir-Kheli, J.K. Yu, W.A. Goddard, J.R. Heath, Silicon nanowires as efficient thermoelectric materials, Nature, 451 (2008) 168-171.

[3] A.I. Hochbaum, R.K. Chen, R.D. Delgado, W.J. Liang, E.C. Garnett, M. Najarian, A. Majumdar, P.D. Yang, Enhanced thermoelectric performance of rough silicon nanowires, Nature, 451 (2008) 163-U165.

[4] O. Caballero-Calero, M. Martin-Gonzalez, Thermoelectric nanowires: A brief prospective, Scripta Materialia, 111 (2016) 54-57.

[5] F. Xiao, C. Hangarter, B. Yoo, Y. Rheem, K.H. Lee, N.V. Myung, Recent progress in electrodeposition of thermoelectric thin films and nanostructures, Electrochimica Acta, 53 (2008) 8103-8117.

[6] U.S. Mohanty, Electrodeposition: a versatile and inexpensive tool for the synthesis of nanoparticles, nanorods, nanowires, and nanoclusters of metals, Journal of Applied Electrochemistry, 41 (2011) 257-270.

[7] J.M. Yang, S.P. Gou, I.W. Sun, Single-step large-scale and template-free electrochemical growth of Ni-Zn alloy filament arrays from a zinc chloride based ionic liquid, Chemical Communications, 46 (2010) 2686-2688.

[8] M. Steichen, P. Dale, Synthesis of trigonal selenium nanorods by electrodeposition from an ionic liquid at high temperature, Electrochemistry Communications, 13 (2011) 865-868.

[9] Y.T. Hsieh, M.C. Lai, H.L. Huang, I.W. Sun, Speciation of cobalt-chloride-based ionic liquids and electrodeposition of Co wires, Electrochimica Acta, 117 (2014) 217-223.

[10] G. Absalan, M. Akhond, H. Ershadifar, M.A. Rezaei, Two-approach study for preparing stable colloidal gold nanoparticles in organic solvents by using 1-dodecy1-3methylimidazolium bromide as an efficient capping and phase transfer agent, Colloids and Surfaces a-Physicochemical and Engineering Aspects, 486 (2015) 192-202.

[11] R. Al-Salman, H. Sommer, T. Brezesinski, J. Janek, Template-Free Electrochemical Synthesis of High Aspect Ratio Sn Nanowires in Ionic Liquids: A General Route to LargeArea Metal and Semimetal Nanowire Arrays?, Chemistry of Materials, 27 (2015) 3830-3837.

[12] J. Szymczak, S. Legeai, S. Diliberto, S. Migot, N. Stein, C. Boulanger, G. Chatel, M. Draye, Template-free electrodeposition of tellurium nanostructures in a room-temperature ionic liquid, Electrochemistry Communications, 24 (2012) 57-60.

[13] L. Thiebaud, S. Legeai, N. Stein, Tuning the morphology of Te one-dimensional nanostructures by template-free electrochemical deposition in an ionic liquid, Electrochimica Acta, 197 (2016) 300-306. 
[14] A. Triolo, O. Russina, B. Fazio, G.B. Appetecchi, M. Carewska, S. Passerini, Nanoscale organization in piperidinium-based room temperature ionic liquids, Journal of Chemical Physics, 130 (2009).

[15] Y. Traore, S. Legeai, S. Diliberto, G. Arrachart, S. Pellet-Rostaing, M. Draye, New insight into indium electrochemistry in a Tf2N-based room-temperature ionic liquid, Electrochimica Acta, 58 (2011) 532-540.

[16] J. Szymczak, S. Legeai, S. Michel, S. Diliberto, N. Stein, C. Boulanger, Electrodeposition of stoichiometric bismuth telluride Bi2Te3 using a piperidinium ionic liquid binary mixture, Electrochimica Acta, 137 (2014) 586-594.

[17] M. Yamagata, N. Tachikawa, Y. Katayama, T. Miura, Electrochemical behavior of several iron complexes in hydrophobic room-temperature ionic liquids, Electrochimica Acta, 52 (2007) 3317-3322.

[18] T. Iwasita, M.C. Giordano, Kinetics of the bromine-tribromide-bromide redox processes on platinum electrodes in acetonitrile solutions, Electrochimica Acta, 14 (1969) 1045-1059.

[19] A.I. Popov, D.H. Geske, Studies on the chemistry of halogen and of polyhalides. XVI. Voltammetry of bromine and interhalogen species in acetonitrilr, Journal of the American Chemical Society, 80 (1958) 5346-5349.

[20] E.G.S. Jeng, I.W. Sun, Electrochemistry of tellurium(IV) in the basic aluminum chloride1-methyl-3-ethylimidazolium chloride room temperature molten salt, Journal of the Electrochemical Society, 144 (1997) 2369-2374.

[21] R.W. Tsai, Y.T. Hsieh, P.Y. Chen, I.W. Sun, Voltammetric study and electrodeposition of tellurium, lead, and lead telluride in room-temperature ionic liquid 1-ethyl-3methylimidazolium tetrafluoroborate, Electrochimica Acta, 137 (2014) 49-56.

[22] S. Saha, N. Tachikawa, K. Yoshii, Y. Katayama, Electrodeposition of Selenium in a Hydrophobic Room-Temperature Ionic Liquid, Journal of the Electrochemical Society, 163 (2016) D259-D264.

[23] N. Borisenko, A. Ispas, E. Zschippang, Q. Liu, S.Z. El Abedin, A. Bund, F. Endres, In situ STM and EQCM studies of tantalum electrodeposition from TaF5 in the air- and waterstable ionic liquid 1-butyl-1-methylpyrrolidinium bis(trifluoromethylsulfonyl)amide, Electrochimica Acta, 54 (2009) 1519-1528.

[24] Y.T. Hsieh, Y.C. Chen, I.W. Sun, 1-Butyl-1-Methylpyrrolidinium Dicyanamide Room Temperature Ionic Liquid for Electrodeposition of Antimony, Journal of the Electrochemical Society, 163 (2016) D188-D193.

[25] T. Carstens, R. Gustus, O. Hofft, N. Borisenko, F. Endres, H. Li, R.J. Wood, A.J. Page, R. Atkin, Combined STM, AFM, and DFT Study of the Highly Ordered Pyrolytic Graphite/1Octyl-3-methyl-imidazolium Bis(trifluoromethylsulfonyl)imide Interface, Journal of Physical Chemistry C, 118 (2014) 10833-10843. 


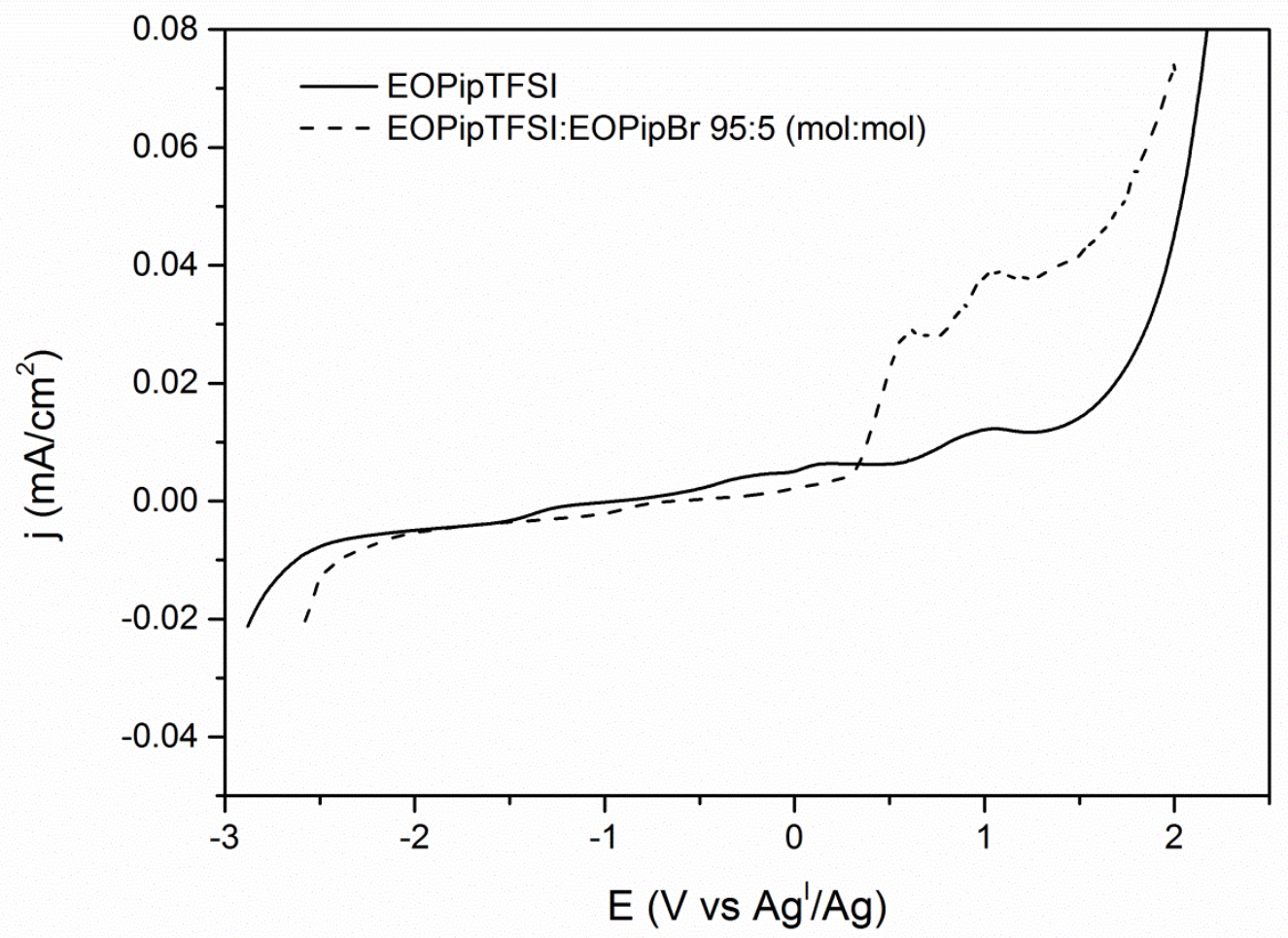

Figure 1: Electrochemical stability of EOPipTFSI and EOPipTFSI:EOPipBr 95:5 electrolyte.

Pt disk working electrode. $\mathrm{T}=100^{\circ} \mathrm{C}$, scan rate $=5 \mathrm{mV} / \mathrm{s}$. 


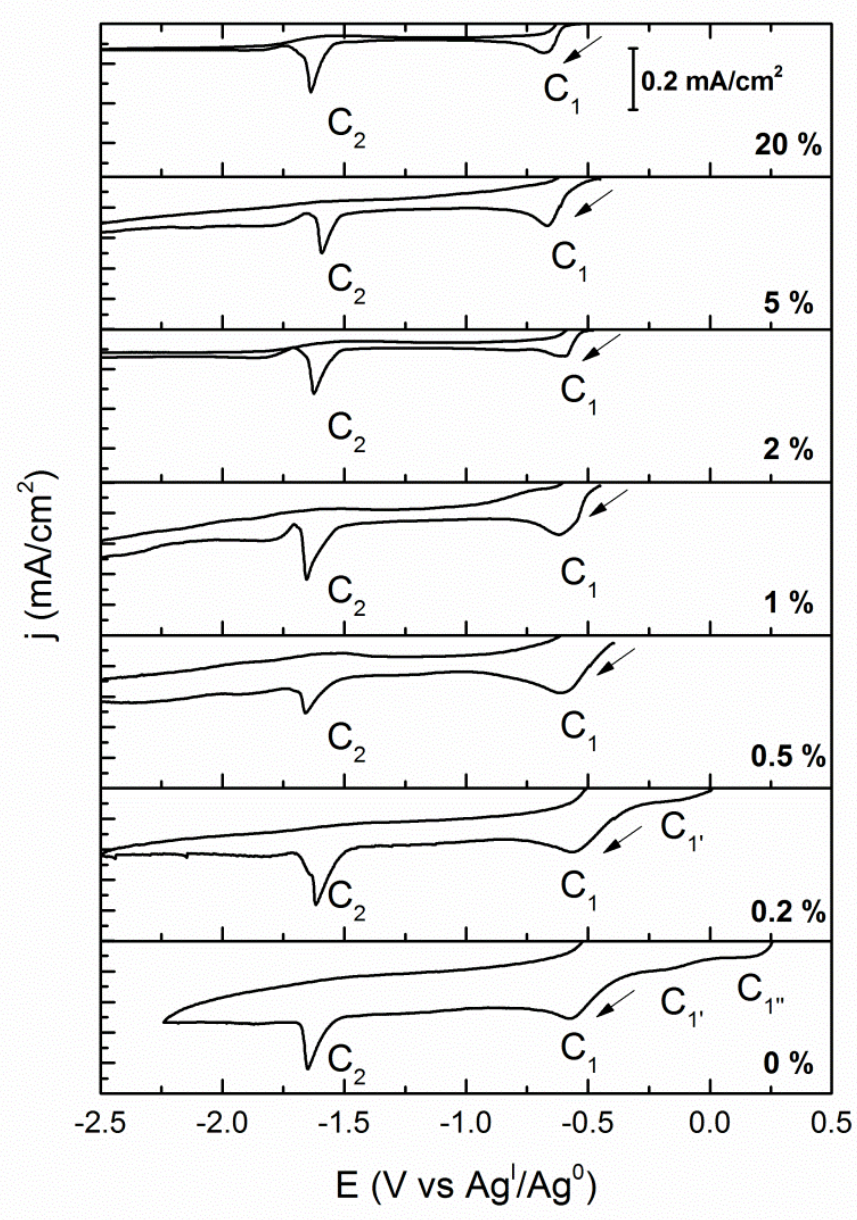

Figure 2: Cathodic behavior of $\mathrm{Te}^{\mathrm{IV}}$ in EOPipTFSI for several EOPipBr contents (mol\%). $\left[\mathrm{TeCl}_{4}\right]=5 \mathrm{mM}$. Pt disk working electrode. $\mathrm{T}=100^{\circ} \mathrm{C}$, scan rate $=5 \mathrm{mV} / \mathrm{s}$. 

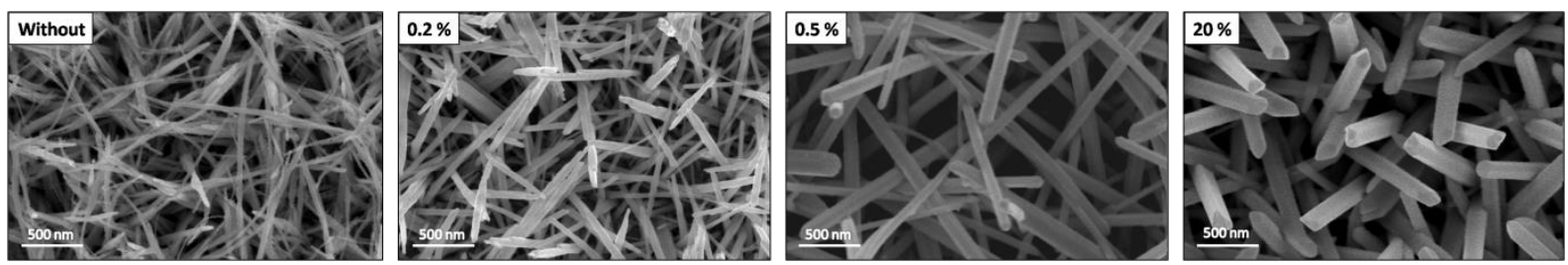

Figure 3: SEM images of Te nanostructures electrodeposited at $\mathrm{C}_{1}$ peak potential in pure EOPipTFSI and three EOPipTFSI:EOPipBr melts $\left(\mathrm{mol}^{2}\right) \cdot\left[\mathrm{TeCl}_{4}\right]=5 \mathrm{mM} . \mathrm{T}=100^{\circ} \mathrm{C}, \mathrm{Q}=$ $2 \mathrm{C} / \mathrm{cm}^{2}$, Pt-coated glass slide.

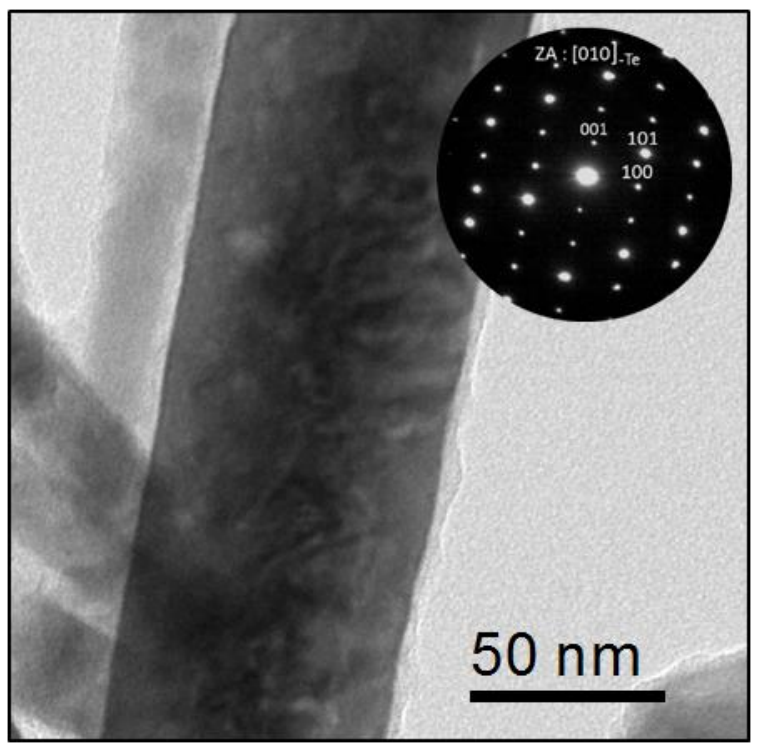

Figure 4: TEM images and SAED pattern of Te nanowires obtained without EOPipBr. 

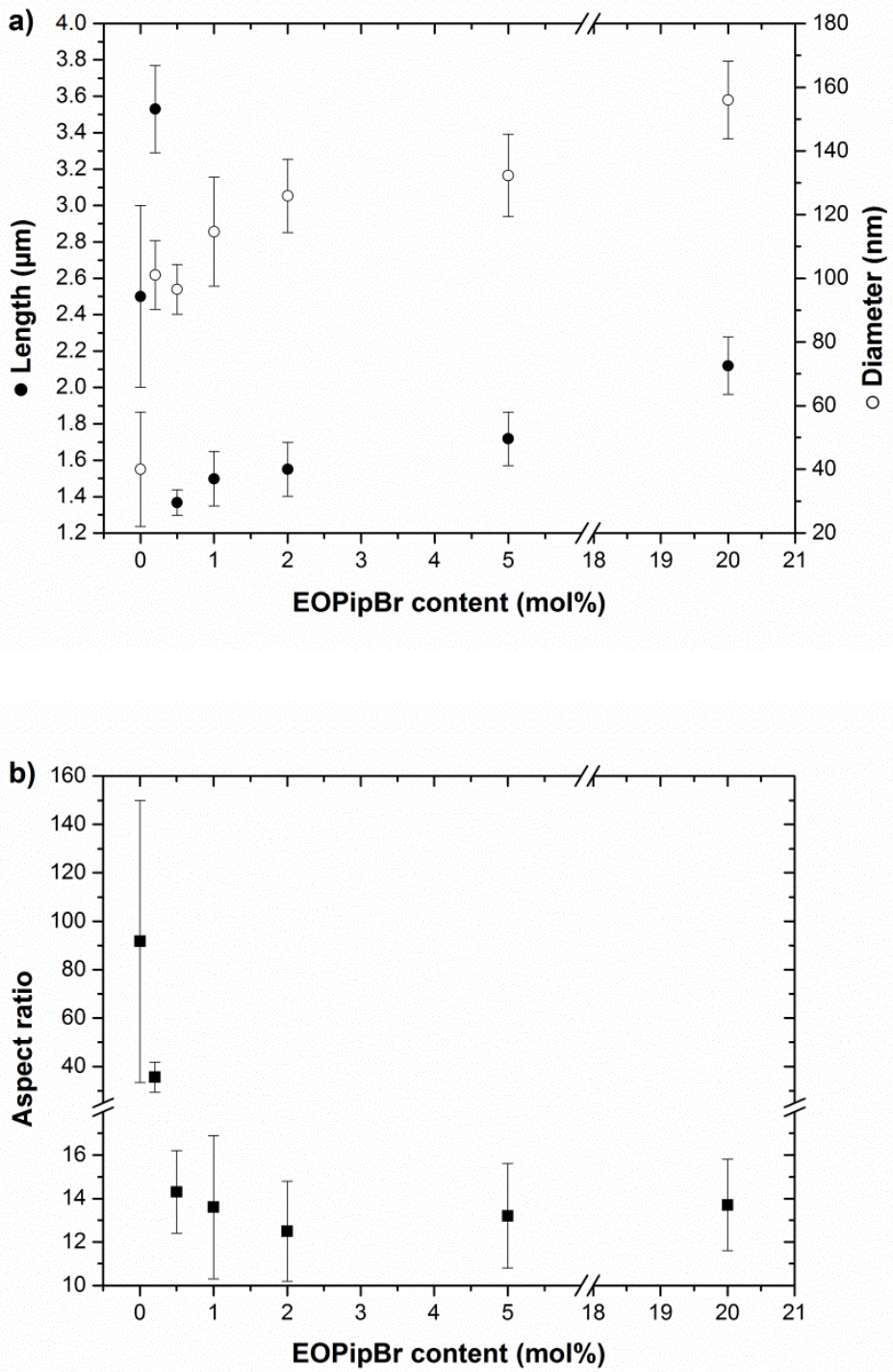

Figure 5: Evolution of a) length and diameter and b) aspect ratio of Te nanowires obtained at $\mathrm{C}_{1}$ peak potential according to the EOPipBr concentration $(\mathrm{mol} \%),\left[\mathrm{Te}^{\mathrm{IV}}\right]=5 \mathrm{mM}$. 


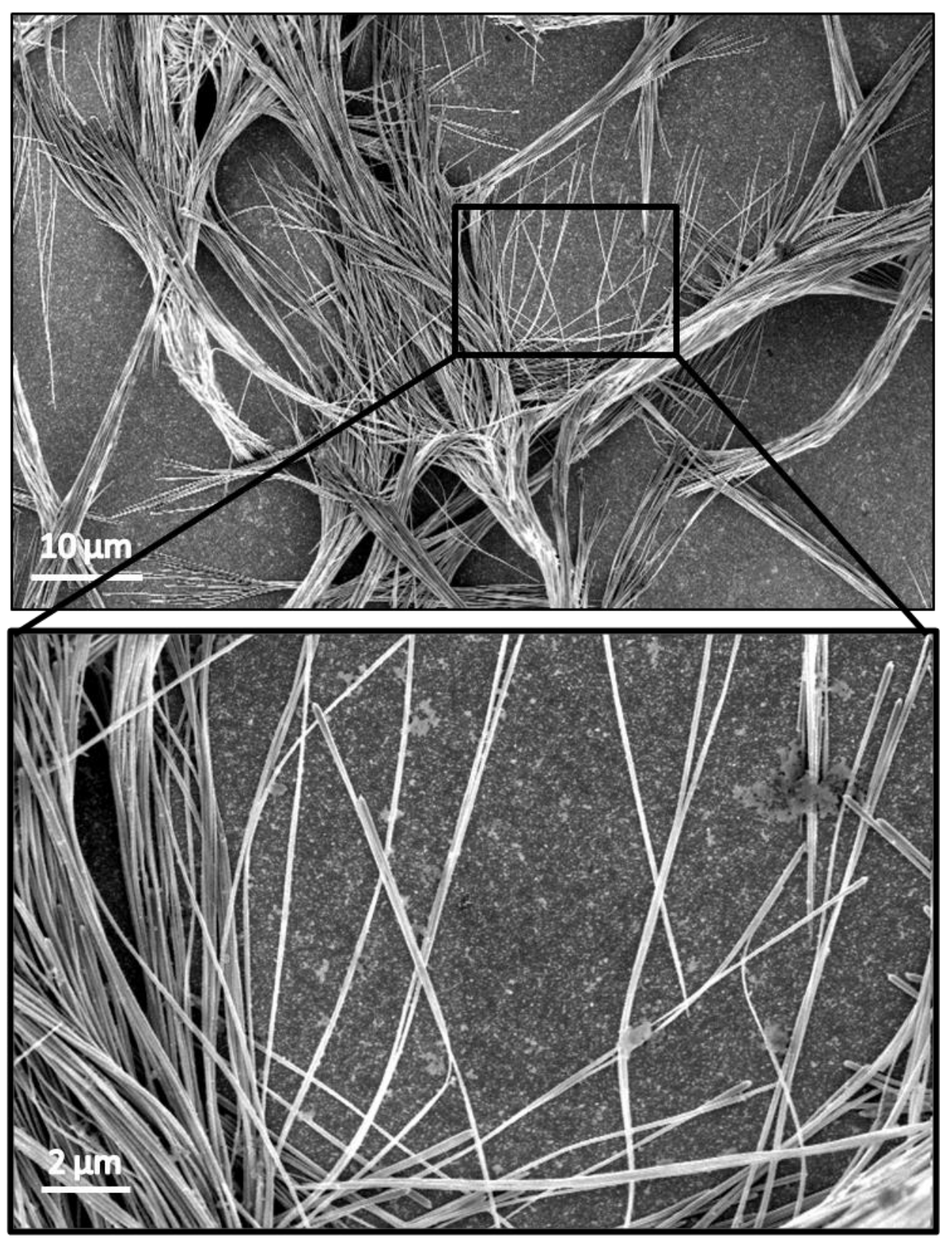

Figure 6 : SEM images of Te nanowires deposited at $\mathrm{C}_{1}$ ", peak potential in pure EOPipTFSI. $\left[\mathrm{Te}^{\mathrm{IV}}\right]=5 \mathrm{mM} . \mathrm{T}=100^{\circ} \mathrm{C}, \mathrm{Q}=2 \mathrm{C} / \mathrm{cm}^{2}$, Pt-coated glass slide. 

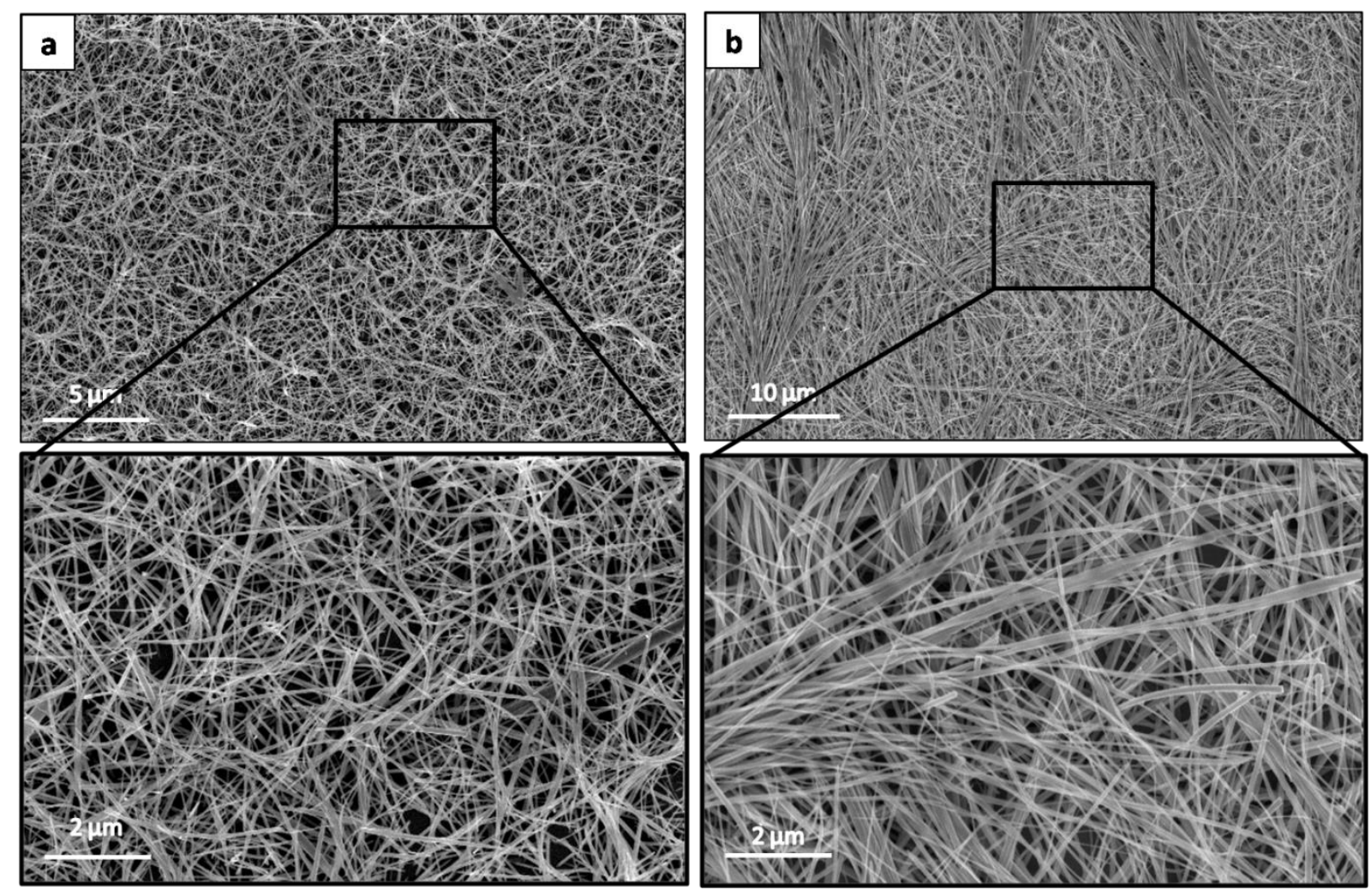

Figure 7 : SEM images of Te nanostructures deposited at $\mathrm{C}_{1}$, peak potential (a) in pure

EOPipTFSI and (b) with a EOPipBr content of $0.2 \mathrm{~mol} \% \cdot\left[\mathrm{Te}^{\mathrm{IV}}\right]=5 \mathrm{mM} . \mathrm{T}=100^{\circ} \mathrm{C}, \mathrm{Q}=2$

$\mathrm{C} / \mathrm{cm}^{2}$, Pt-coated glass slide. 

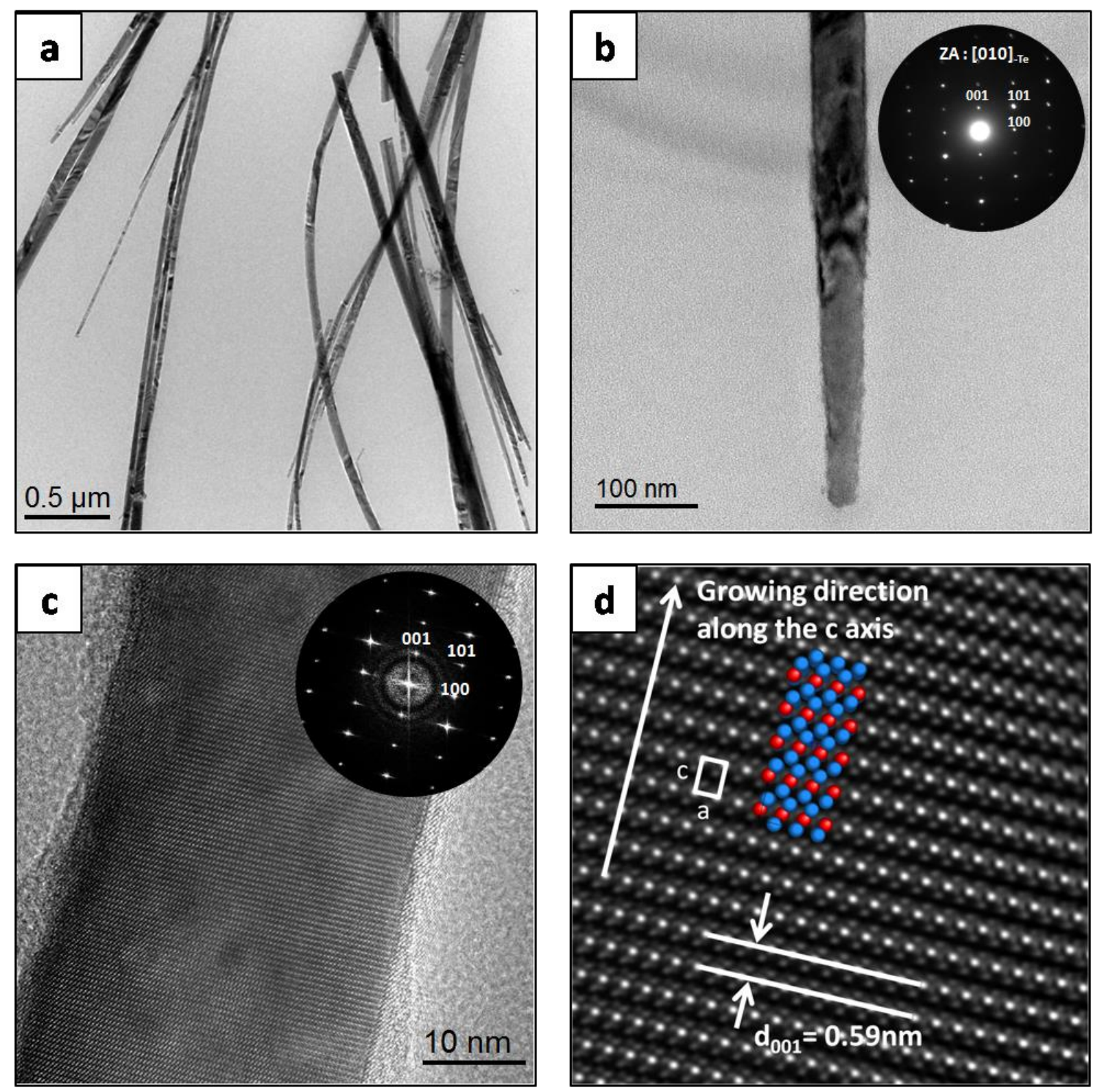

Figure 8 : TEM characterization of Te hair-like nanowires obtained at $\mathrm{C}_{1}$, potential peak in EOPipTFSI with 0.2 mol\% of EOPipBr: a) TEM image of a Te nanowires group, b) TEM micrograph and corresponding SAED pattern indexed to the tellurium phase (JCPDS card No. 36-1452), c) HRTEM micrograph with Fast Fourier Transform (FFT) and d) Image of inverse FFT with Te crystallographic structure along the $[010]$ zone axis. $\left[\mathrm{Te}^{\mathrm{IV}}\right]=5 \mathrm{mM} . \mathrm{T}=100^{\circ} \mathrm{C}$, $\mathrm{Q}=2 \mathrm{C} / \mathrm{cm}^{2}$, Pt-coated glass slide. 


\begin{tabular}{|c|c|}
\hline $\begin{array}{l}\text { EOPipBr content } \\
\qquad(\mathrm{mol} \%)\end{array}$ & {$\left[\mathrm{X}^{-}\right] /\left[\mathrm{Te}^{\mathrm{IV}}\right]$} \\
\hline 0 & 4.00 \\
\hline 0.2 & 4.97 \\
\hline 0.5 & 6.43 \\
\hline 1 & 8.88 \\
\hline 2 & 13.78 \\
\hline 5 & 28.68 \\
\hline 20 & 107.00 \\
\hline
\end{tabular}

Table 1: $\mathrm{X}^{-}$to $\mathrm{Te}^{\mathrm{IV}}$ concentration ratio according to the EOPipBr content (mol\%). $\left[\mathrm{X}^{-}\right]=\left[\mathrm{Cl}^{-}\right]$ $+\left[\mathrm{Br}^{-}\right]$ 